\title{
THE TEACHER'S ROLE IN THE BATTLE OF THE INTELLIGENT MACHINES
}

\author{
Andrej Šorgo \\ University of Maribor, Slovenia
}

Since the invention of smart pocket devices with the strength of supercomputers from the past, we have witnessed that the young are organizing their lives around these devices (Boyd, 2014). In this way, what should take place in their leisure time is now done in schools, and what should take place in schools is allocated to their leisure time. One of the school-related activities invading their devices is the assessment and grading of their knowledge. From the standpoint of a teacher, there are many good reasons to put assessment and self-educational interactive tools on-line, although there are also many reasons why this should be done with care.

For most educators, grading and marking assignments are not high on their wish lists for their teaching routines. In the context of learning, the same can be said for their students, where examinations are associated with feelings such as insecurity, anxiety, fear, and stress. For diverse reasons, such as allowing students to self-assess their knowledge or providing homework, many teachers who are more advanced in the application of ICT, are already putting quizzes and tests online. Nowadays, such tests are in most cases delivered and assessed automatically, with an automatic system. Often, such basic systems provide feedback to the students if an answer is correct and a summary of the outcome. So far, so good - after testing, students know what they still have to learn and what they have already learned. Equally, teachers get the same information about the students. In this way, a teacher's time can be spent on better purpose. However, the drawback is that tests are uniform in the format of the templates provided by the system, the philosophy of test construction and the grading by their developers. Additionally, if not controlled, such tests can even be answered by people other than the target students.

In a search for assessment systems reflecting the diversity of students and differences in their knowledge base and abilities, Artificial Intelligence was proposed as a rescue boat. More advanced systems based on Artificial Intelligence can select tasks according to the previous knowledge levels of the students and provide follow-up tasks or explanations so as to help them fill the missing gaps and skip any content already mastered. By analysing the paths of individual students and measuring parameters such as time assigned to an individual task, teachers can get a lot of information, transferring analysis of the data in their leisure time.

However, even the best response systems are still not at the level of being able to assess complex work based on freewriting forms, such as essays or lab reports. Recent solutions can help in the identification of spelling mistakes, and in a more advanced form with grammar, syntax, and plagiarism. However, they still cannot assess the meaningfulness and correctness of the content. To be brutal, even the greatest idiocy could be written and argued in bullet-proof language and would remain unnoticed by the intelligent systems. Teachers are thus saved from having to correct spelling mistakes and language errors, but they still need to check and review the content and logic of argumentation.

In the future, it is easy to imagine a teacher's heaven, where a student submits an essay or project to an online system. In a matter of seconds, the system counts the spelling mistakes, discrepancies from the template, syntax errors, inconsistencies between theory, results, discussion and conclusions, checks for plagiarism, and finally provides a suggested grade in a range of $p<.05$ levels, with a $5 \%$ confidence interval. All a teacher must do then is to add a personal impression about the student, after consulting an already compiled personal profile based on a number of previous sessions. 
ISSN 1648-3898 /Print/

ISSN 2538-7138/Online/

What will remain unnoticed by the teacher is that the submitted essay could already have been checked and corrected by an alternative intelligent system in the best variant, or - in the worst case - completely written by the other system. Such systems are in the infant phase at the moment; however, after testing some of them, I was impressed. Not wanting to advertise any particular brand, I can still affirm they are now able to produce readable, meaningful articles and blog contributions in a matter of seconds, based on the input of just a few keywords. At the moment, even the best such systems cannot provide lengthy texts, although that could change rapidly; however, they do offer "unique articles free from plagiarism and duplications" and references within and at the end of the paper.

What can be said ultimately? The first option is to leave the battle to the intelligent machines, with teachers as observers. The second option is to include a line in the list of teachers' competencies and blame them later if they are digitally incompetent. The third is to transfer the students' work back to the school, where a community of students and a teacher will solve authentic and inquiry-based problems with solutions and outcomes beyond the imaginary of Artificial Intelligence and article generators. In such an approach, reports would be a by-product of the work and not the ultimate goal. And, of course, attributed work should be well balanced between students as inquirers and teachers as their guides (Hmelo-Silver, Duncan, \& Chinn, 2007; Kirschner, Sweller, \& Clark, 2006; Oliver, McConney, \& Woods-McConney, 2019; Sweller, Kirschner, \& Clark, 2007).

\section{References}

Boyd, D. (2014). It's complicated: The social lives of networked teens. Yale University Press.

Hmelo-Silver, C. E., Duncan, R. G., \& Chinn, C. A. (2007). Scaffolding and achievement in problem-based and inquiry learning: A response to Kirschner, Sweller, and Clark (2006). Educational Psychologist, 42(2), 99-107. https://doi. org/10.1080/00461520701263368

Kirschner, P. A., Sweller, J., \& Clark, R. E. (2006). Why minimal guidance during instruction does not work: An analysis of the failure of constructivist, discovery, problem-based, experiential, and inquiry-based teaching. Educational Psychologist, 41(2), 75-86. https://doi.org/10.1207/s15326985ep4102_1

Oliver, M., McConney, A., \& Woods-McConney, A. (2019). The efficacy of Inquiry-Based instruction in science: A comparative analysis of six countries using PISA 2015. Research in Science Education, 1-22. https://doi.org/10.1007/s11165-019-09901-0

Sweller, J., Kirschner, P. A., \& Clark, R. E. (2007). Why minimally guided teaching techniques do not work: A reply to commentaries. Educational Psychologist, 42(2), 115-121. https://doi.org/10.1080/00461520701263426 